\title{
30 Years of Transmission Electron Microscopy (TEM) at the Wyoming State Veterinary Laboratory, Laramie, WY as an Aid for Virus Diagnosis
}

\author{
C.E. Hearne, J.C. Cavender, and M.M. Miller \\ Department of Veterinary Sciences, University of Wyoming, Laramie, WY 82070
}

In 1980, the Wyoming State Veterinary Laboratory (WSVL), Laramie, WY added transmission electron microscopy (TEM) to the diagnostic laboratory to compliment other testing provided. Specimens from many animal species have been received for diagnosis through the years including livestock animals, domestic pets, and domestic birds. A variety of wildlife animal submissions such as elk, deer, wild carnivores, wild avian, big horn sheep, rabbits, rodents, reptiles, and more have also been submitted to the WSVL. Interesting and sometimes unexpected or novel viruses have been documented by TEM and many of the cases submitted have excited interest with our scientists, pathologists and technicians.

For over 30 years, TEM has proven to be a useful and reliable tool aiding in the virus identification from clinical animal specimens submitted to the WSVL. Negative contrast electron microscopy (NCEM) is utilized in our laboratory as an effective and efficient method to recognize the presence of viral particles in the clinical specimens submitted ${ }^{1-4}$ (Figs. 1a, 2-7). Many times, TEM examination of submitted diagnostic tissues and cell cultures provides useful viral identification before other laboratory diagnostic results are available, and knowing the virus family furnishes valuable information for additional laboratory testing, such as polymerase chain reaction (PCR). TEM is also used to verify virology fluorescent antibody (FA) examinations and can be used to validate virus isolation assays. Ultrathin sectioning of resin embedded tissues and cell cultures from selected animal specimen submissions has helped at times to further the investigation and diagnosis of viral diseases in some of the animal cases ${ }^{1,4,5}$ (Fig. 1a, 1b).

The coordination of the WSVL laboratory test(s) results, along with the herd or animal's clinical history enable our pathologists to make final diagnoses. The diagnostic results offer valuable information to submitting veterinarians helping them provide the best care for the animals involved including wildlife management, herd health assessments, and educating the animal owners.

\section{References}

[1] G.D. Hsiung et al, Diagnostic Virology As Illustrated By Light and Electron Microscopy $4^{\text {th }}$ Addition, Yale Univ. Press, New Haven, 1994

[2] H.K.Whitaker and C. Alderson, Amer. Assn. Vet. Diag. 23 ${ }^{\text {rd }}$ Ann. Proceed. (1980) 321.

[3] S.E. Miller, EMSA Bulletin. 19 (1989) 53.

[4] C.E. Hearne et al., Microsc. Microanal. 14(Suppl. 2) (2008) 1544.

[5] M.A. Hayat, Principles and Techniques of Electron Microscopy, Biological Applications, Edward Arnold (Publishers), London, 1981 

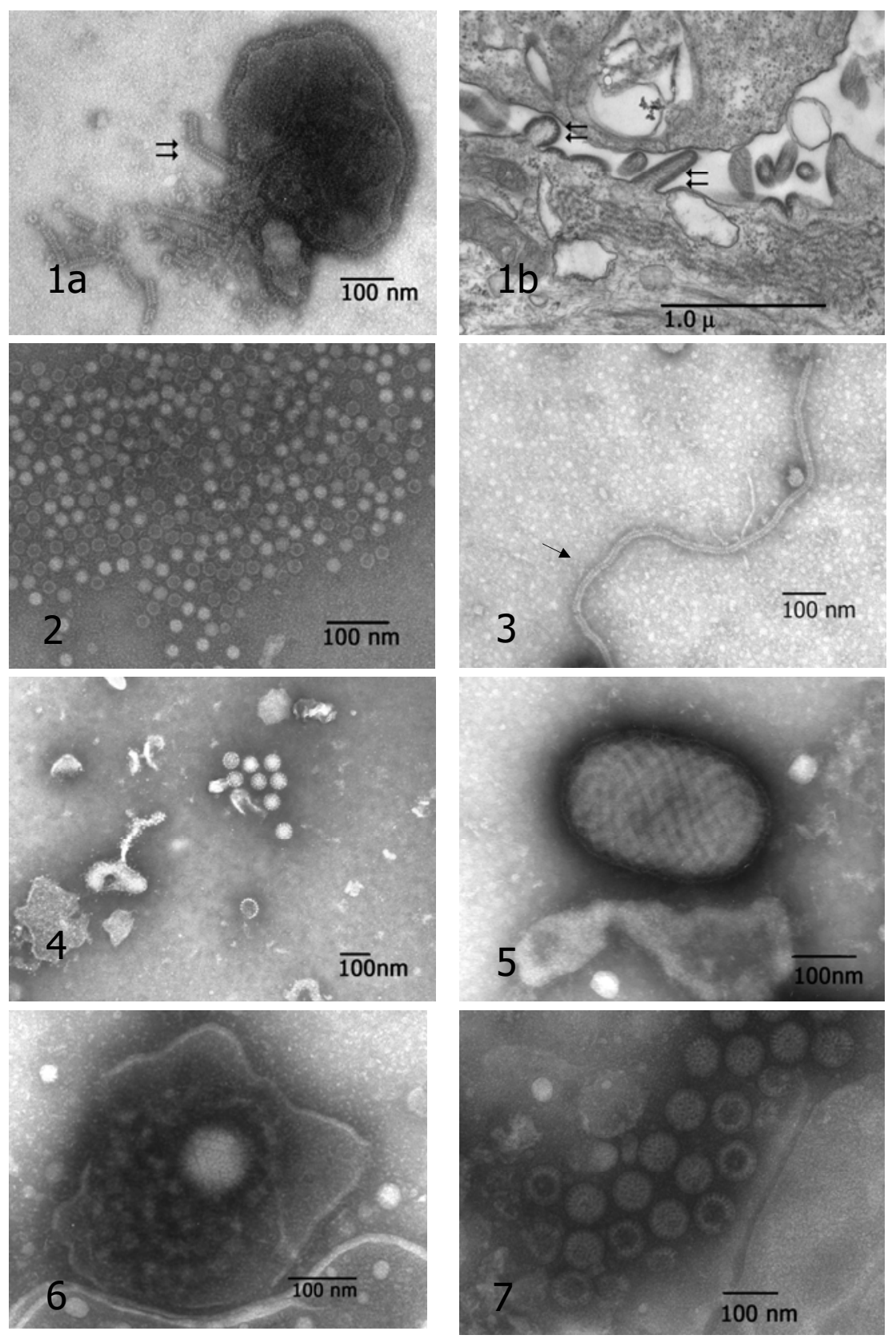

FIGS. 1a and1b. Paramyxovirus from domestic lamb. A. NCEM of Paramyxovirus releasing helical nucleocapsids with "herringbone" morphology (arrows). Marker $=100 \mathrm{~nm}$

B. Ultrathin section of resin embedded Paramyxovirus inoculated MDBK cell culture. Virus is budding at the cell membrane (arrows). Marker $=1.0 \mu$

FIG. 2. NCEM of Parvovirus from dog intestine. Marker $=100 \mathrm{~nm}$

FIG. 3. NCEM of Paramyxovirus helical nucleocapsids from rattlesnake oral swab (arrow).

Marker $=100 \mathrm{~nm}$

FIG. 4. NCEM of Papovavirus from coyote oral (lip) lesion. Marker $=100 \mathrm{~nm}$

FIG. 5. NCEM of Parapoxvirus from domestic sheep skin lesion. Marker $=100 \mathrm{~nm}$

FIG. 6 NCEM of Herpesvirus from great horned owl liver. Marker $=100 \mathrm{~nm}$

FIG. 7. NCEM of Rotavirus from bovine feces. Marker $=100 \mathrm{~nm}$ 